\title{
Critical issues in Melanoma Follow-up and Treatment, Safety of Patients and Communication with Healthcare Professionals during
} Covid-19 pandemic in Romania - a perspective of the Romanian Melanoma Association

\author{
Violeta Astratinei ${ }^{1,2}$, Andreea Strambu-Dima ${ }^{1}$, Bettina Ryll ${ }^{2}$ \\ ${ }^{1}$ Romanian Melanoma Association, Bucharest, Romania \\ 2 Melanoma Patient Network Europe, Uppsala, Sweden
}

Corresponding Author: Violeta Astratinei e-mail: violeta.astratinei@mpneurope.org

\begin{abstract}
Background: The Covid-19 pandemic has significantly impacted cancer care worldwide. The aim of this study was to capture the impact of Covid-19 on melanoma patients during the national state of emergency.

Material and methods: We sent a survey to the members of the Romanian Melanoma patient community between April - May 2020.

Results: We received feedback from 108 patients. Forty percent of the respondents experienced difficulties in accessing healthcare services, while $56 \%$ found it difficult or impossible to speak with their physician. With regard to feeling safe in healthcare facilities, $60 \%$ of patients felt safe in the private sector, versus $48 \%$ in public hospitals. Over half of the respondents delayed investigations such as dermoscopy, imaging, and laboratory tests by their own initiative, while a third saw investigation delayed upon their physician's initiative. We found no significant delays in the administration of systemic therapies for advanced disease. While e-prescriptions for melanoma treatments were not communicated and implemented consistently, we noted an increased interest in telemedicine and social media networks by physicians.

Spontaneous patient reports collected in the same period further show the lack of access to melanoma diagnostic surgery, insufficient management of side effects of different treatments, difficulties in obtaining pain medication, alterations in the administration schemes of both immunotherapies and target therapies, and cumbersome access to Covid-19 testing.

Conclusions: Our results provide a melanoma-specific perspective on the impact of Covid-19 on patients that is unexpectedly nuanced with regards to patient subpopulations and captures differences in impact between systemic treatment and
\end{abstract}


other interventions. In addition, this proof-of-concept study demonstrates the ability of virtual patient communities to sensitively detect and report issues in health care provision, offering the opportunity for timely intervention. Based on our findings, we formulate a set of recommendations on how to save-guard melanoma care during the pandemic, some of which we believe to be generalizable to other patient communities.

Keywords: melanoma, Covid-19 impact, cancer care, access, patient organisation

\section{Introduction}

According to the World Health Organization (WHO), the Covid-19 pandemic has substantially impacted cancer care worldwide [1] with negative effects on the prevention, diagnosis, and treatment of cancer patients. Cancer societies such as the American Society of Clinical Oncology (ASCO) and the European Society of Medical Oncology (ESMO) have issued guidance on how to ensure best-possible cancer care under Covid-19, prioritising clinical settings and the necessity for hospital visits from high to low [2-3].

Initially, and in the absence of sufficient evidence, all cancer patients were classified as 'Covid-19 vulnerable', irrespective of age, tumour type, stage of disease or treatment. This led to the indiscriminate cancellation of interventions and follow-up visits and changes to disease management, notably a switching from intravenous to oral therapies and the general avoidance of immunotherapy for fear of toxicity [3].

In Romania, the first Covid-19 patient was diagnosed on 26th February 2020, followed by the declaration of the state of emergency nearly a month later [4]. Since then, the Romanian government and professional cancer societies recommended and implemented a series of Covid-19 cancerrelated measures to decrease the burden on healthcare services and to protect cancer patients [5]. However, ambiguity in the first set of governmental actions led to variable interpretation and even abuse as reported by cancer patients in public media [6]. The Romanian healthcare system is one of the most under-performing in Europe and has for several years in a row ranked last in the Euro Health Consumer Index (EHCl) reports [7-9]. The Romanian Health Observatory (RHO) reported a worrying drop of $46 \%$ in the number of hospitalisations of cancer patients [10] and a dramatic decrease in activity of hospitals and family practitioners between April and August 2020. According to the same source, more than $50 \%$ of Romanian patients reported that Covid-19 negatively affected their care and $77.5 \%$, considered it affected their health condition, consistent with our findings presented here.

Melanoma is the most aggressive form of skin cancer, and its incidence in Romania $(7.9 / 100000)$ is likely to be underestimated [11]. In 2011, the Cluj Cancer Registry reported an incidence of 9.7/100 000 in male patients and 10.73/100 000 in female patients for Cluj County [12] while Timişoara reported 
$12 / 100000$ in 2008 [13]. Curative by surgery for a high percentage of patients, metastatic melanoma has an infaust prognosis of median survival of 6-9 months in the absence of effective therapies. Thanks to the introduction of novel, highly effective but also costly therapies (immune therapies with antiPD1 and anti-CTL4, and targeted therapies for BRAF mutant melanoma), overall survival has now considerably increased to over $50 \%$ at five years [14]. In this setting, access to early diagnosis and surgical treatment, as well as continuous access to systemic therapies and monitoring are critical for the survival of our patient population.

Romanian melanoma patients are among the few Romanian cancer communities that benefit from a dedicated cancer-specific patient organisation in their native language. Founded in 2015, the Romanian Melanoma Association is a national network of melanoma patients, care-givers and patient advocates, affiliated to the Melanoma Patient Network Europe (MPNE).

Here we report the results of a survey conducted within the Romanian Melanoma Association during the Covid-19 state of emergency in Romania. The Health Ministry implemented the first severe Covid-19-related measures between $16^{\text {th }}$ and 23rd March 2020. On 14th April, the Ministry revised its position, now permitting hospitals to admit patients whose survival could be compromised by increased waiting times for diagnosis and treatment and our survey Covid-19 Impact on Romanian Melanoma Patients was launched as a response on April 18th.

\section{Methods}

We surveyed the members of the Romanian Melanoma Association between 18th of April and 18th of May during the state of emergency in Romania to capture how the lockdown affected the access to health care for melanoma patients. The survey comprised 21 questions, covering six domains: patients' characteristics, perception of access to healthcare, perception of safety in healthcare units, communication with the healthcare provider, delays in investigations and e-prescriptions.

The survey was distributed via the Romanian Melanoma network. The private group consists of over 940 members. Considering the small target population melanoma patients in Romania - we believe the return of 108 respondents being representative.

No personal data were collected, and the questionnaire could not be traced back to individual patients. The data were analysed with IBM SPSS Statistics 25.0.

To protect respondents' privacy in the small target group and to encourage participation as patients are sometimes worried to report negative experiences for fear of repercussions, non-traceable information like names, nor information on sex and age were collected.

For context and illustration, we include comments submitted in the free text sections of the survey as well as spontaneous patient reports from our online forums collected during the same period. To our knowledge, there are no previous reports on how Covid- 
19 has impacted melanoma patients in Romania.

\section{Results}

\subsection{Patients' Characteristics}

Patients' Characteristics are presented in Table 1. The survey was completed by 108 respondents, $62 \%$ were patients and
$38 \%$ caregivers, who completed the questionnaire on behalf of the patient. $91 \%$ of them were affected by melanoma in different stages. Patients were almost equally divided between public (46\%) and private $(54 \%)$ care, and equally between under treatment $(50 \%)$ and not on treatment (50\%).

\section{Table 1 - Respondents' characteristics}

\begin{tabular}{|l|r|r|}
\hline & Number & $\%$ \\
\hline Respondent's status & & \\
\hline Patient & 41 & 38 \\
\hline Carer & 67 & 62 \\
\hline Type of cancer & & \\
\hline Cutaneous melanoma & 89 & 82 \\
\hline Other type of melanoma & 9 & 8 \\
\hline High risk of developing melanoma & 4 & 4 \\
\hline Other type of cancer & 6 & 6 \\
\hline Stage of melanoma & & \\
\hline 0 & 2 & 2 \\
\hline I & 13 & 12 \\
\hline II & 15 & 14 \\
\hline III & 25 & 23 \\
\hline IV & 37 & 34 \\
\hline Don't know & 9 & 8 \\
\hline Other type of cancer & 7 & 7 \\
\hline Treatment setting & & \\
\hline Under treatment for metastatic disease & 32 & 30 \\
\hline Under treatment in adjuvant setting & 22 & 20 \\
\hline Follow-up & 47 & 44 \\
\hline Awaiting treatment & 7 & 6 \\
\hline Region & & \\
\hline Bucharest metropolitan area & 34 & 31 \\
\hline NE & 15 & 14 \\
\hline S, SV,SE & 33 & 31 \\
\hline W, NW, Centre & 26 & 24 \\
\hline Type of medical facility & 50 & 46 \\
\hline Public & 58 & 54 \\
\hline Private & & \\
\hline
\end{tabular}

Abbreviations:

NE- North-East, S- South, SV- South-West, SE- South-East, W- West, NW- North-West 
To capture geographical distribution, we grouped participants into four areas to balance for population density and the cultural and health similarities between the regions: Bucharest metropolitan area $(31 \%$, including the Bucharest-llfov region), South (31\%, consisting in South, South-West and SouthEast regions), West (24\%, consisting in West, North-West and Central regions) and NorthEast (14\%, representing the North-East region).
3.2. Perception of access to healthcare during the state of emergency

Nearly $40 \%$ of the respondents felt that access to health services was more difficult during the state of emergency than before (Fig.1). Differences between public (42\%) and private $(36 \%)$ systems were not significant in this regard.

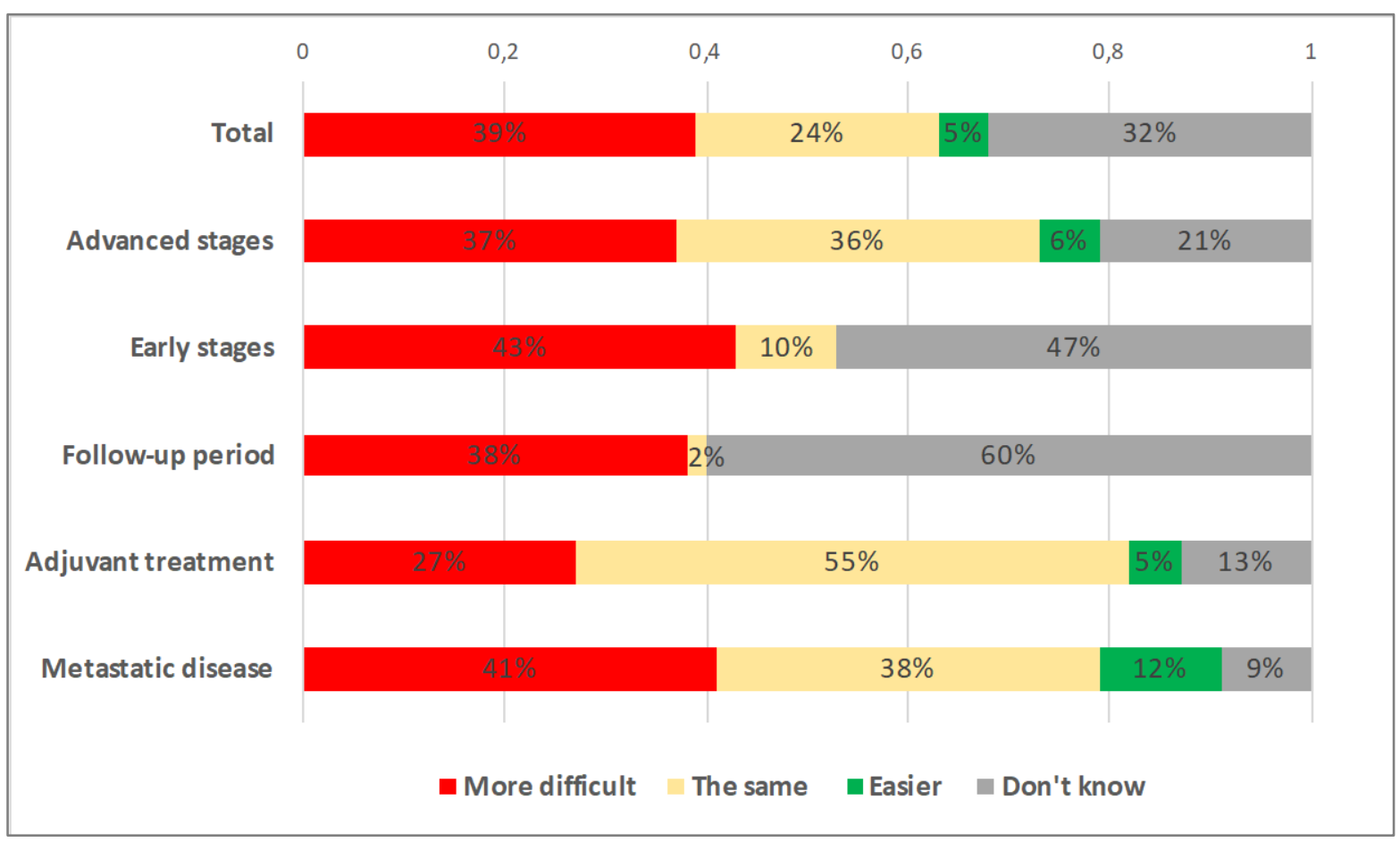

Fig. 1 - Melanoma patients' perception on access to healthcare during the state of emergency

The most dissatisfied about access to healthcare services during the surveyed period were patients on treatment for metastatic disease $(41 \%)$, followed by those during follow-up (38\%) and those on adjuvant therapy (27\%).

Patients with early stages of disease either considered access more difficult $(43 \%)$ or declared that they did not know (47\%), patients with advanced disease considered access more difficult $(37 \%)$ or as usual $(36 \%)$.

$19 \%$ respondents (20 patients) reported that the health facility where they were treated was closed. This was the case for $20 \%$ of patients in the follow-up period, but also for $16 \%$ of patients on treatment for metastatic disease and $9 \%$ of the patients on adjuvant 
therapy. Interestingly, $25 \%$ of patients facing this problem were treated in Bucharest.

With regards to access, respondents specified in the free text section: „There are no funds for my scans", "Dermatology clinics are closed in my city", "I believe they don't do surgeries anymore at the Cancer Institute, the doctor doesn't answer my messages", "There is a waiting list for Sentinel Node Biopsies", indicating a range of issues affecting access to care.
3.3. Perception of safety in healthcare units

Almost $55 \%$ of patients felt safe during their visit to their healthcare unit. Patients felt safer in the private than the public healthcare system ( $60 \%$ versus $48 \%$ ). Two-thirds of the patients with advanced stages of disease $(68 \%)$ felt safe during hospital visits, but only one third $(33 \%)$ of those with early-stage disease (Fig. 2).

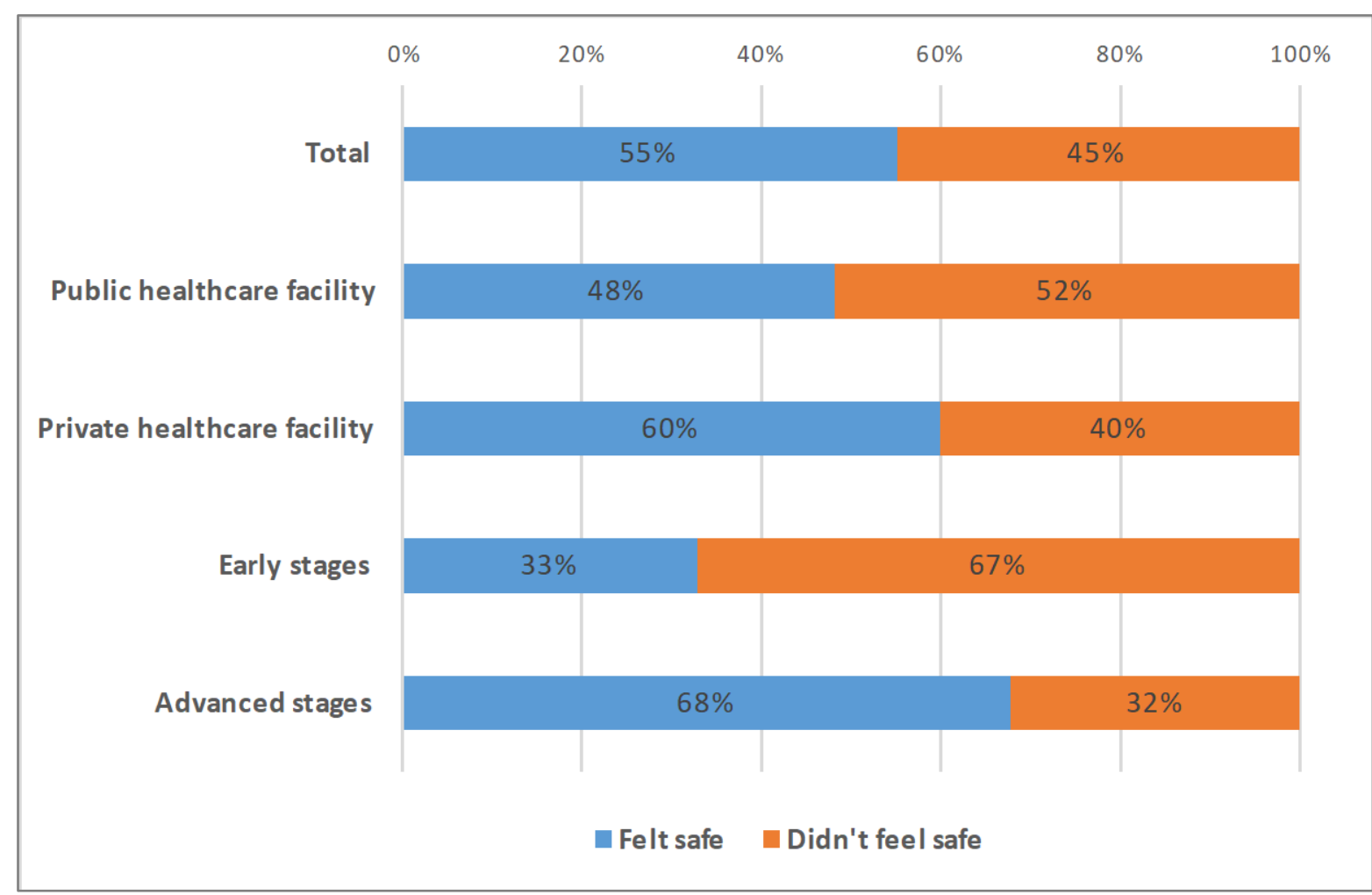

Fig. 2 Melanoma patients' perception on their safety in healthcare facilities during the state of emergency

In the free text section, respondents highlighted both positive and negative experiences: "Conditions are now more civilized in my hospital", "The waiting rooms are not so crowded like before the pandemic", "the medical staff is appropriately equipped". On the contrary, others commented: "I don't feel safe in the public hospitals because of the lack of hygiene and poor handling of the Covid19 situation", "The hospital doesn't schedule appointments", or "There are too many patients, and this is why they cannot maintain the distance". 
3.4. Communication with the healthcare provider during the state of emergency

$44 \%$ of patients said it was easy to communicate with their healthcare provider, $43 \%$ considered it difficult, and $13 \%$ declared they couldn't contact their doctor (Fig. 3). A small subset $(9 \%)$ of patients mentions impoliteness and no explanations regarding their doctor's decision.

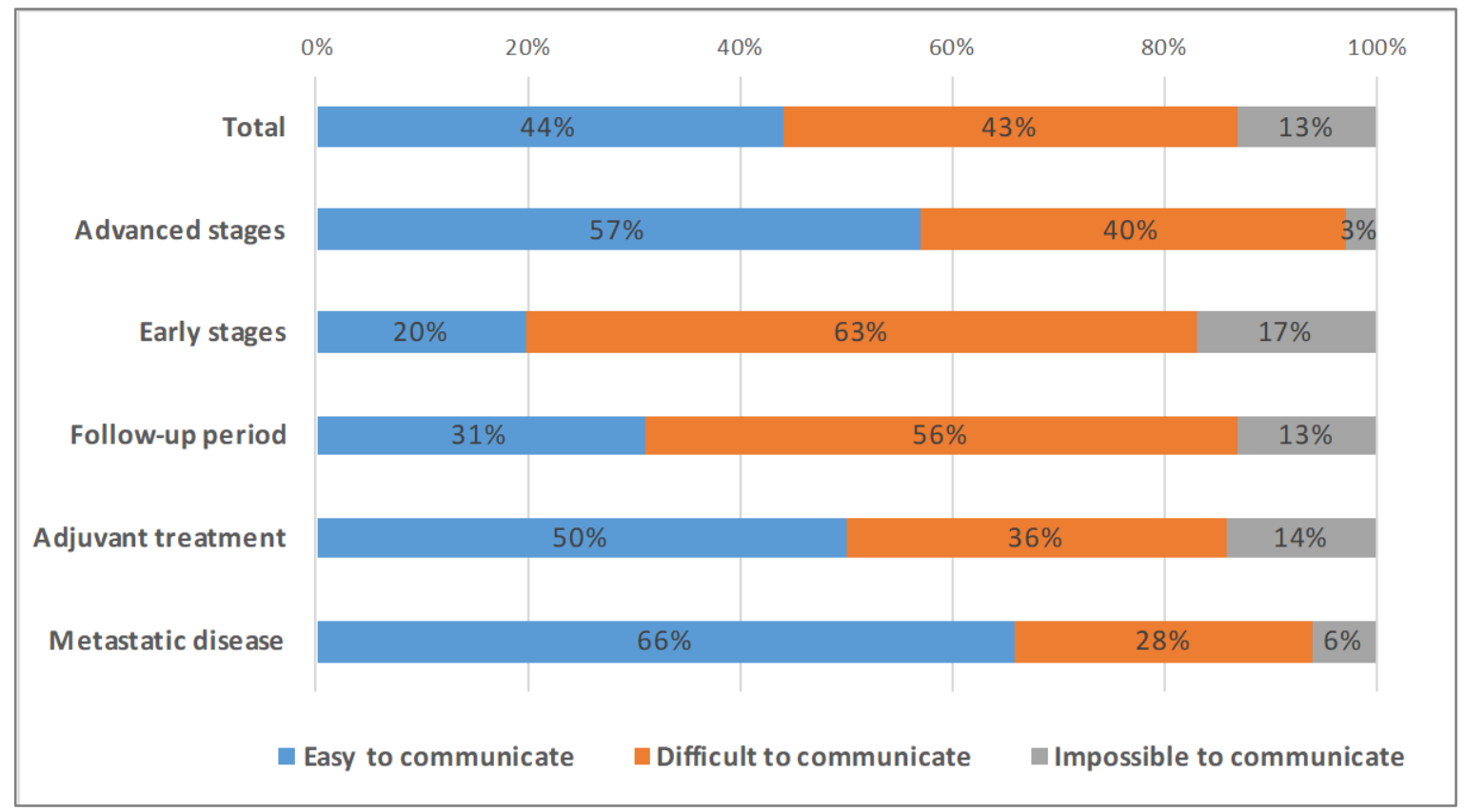

Fig. 3 Melanoma patients' perception on communication with their healthcare provider during the state of emergency

$57 \%$ of patients with advanced stages of the disease reported communication with their healthcare provider as easy, but only $20 \%$ of patients in the early stages. Also, communication seemed easy for $66 \%$ treated for inoperable metastatic melanoma, $50 \%$ of patients on adjuvant therapy, but only $31 \%$ of the patients in the observational (follow up) period.

Only $3 \%$ of the patients on advanced stages of disease declared that communication with their doctor was impossible during the period, in contrast to $17 \%$ for patients in early stages.
Communication channels included mobile phones (including WhatsApp; 59\%), followed by landlines (22\%), and email or online forms (19\%). Unexpectedly for us, some physicians also communicated with their patients on social media, using messenger (14\%), for instance.

We noted differences in geographic distribution, with only $21 \%$ patients in the North-East region considering communication accessible during the lockdown, compared to $44 \%$ in the Bucharest metropolitan area, $46 \%$ in the West (W, NW, Centre), and $52 \%$ in the South (S, SV, SE). 
3.5. Delays in investigations and visits whenever possible. Delays in treatment during the state of emergency

$55 \%$ of respondents were afraid to contract Covid-19 and avoided follow-up investigations and check-ups (Fig. 4) were either initiated by the physician (36\%) or the patient (53\%).

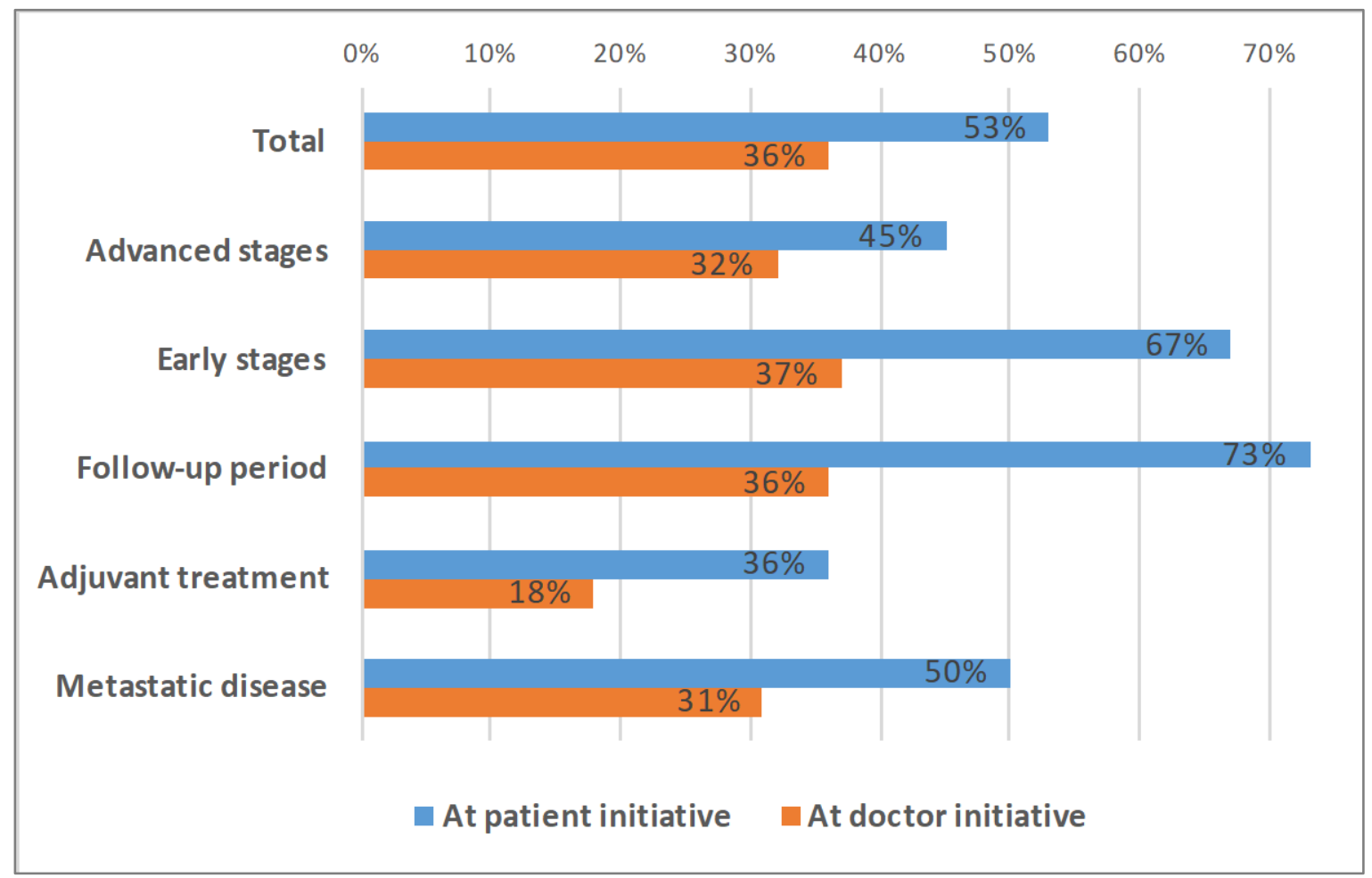

Fig. 4 Melanoma patients' delays in investigations and check-ups during the state of emergency

Patients in the follow-up period were most prone to delays at their own initiative $(73 \%)$, over half of them being early stage patients. It is obvious that patients try to estimate their own risk-benefit ratio for check-ups during Covid-19 pandemic, considering the respondents' percentage that delayed consults at their initiative - only $45 \%$ patients with advanced disease versus $67 \%$ patients with early-stage disease: only $36 \%$ on adjuvant therapy and $50 \%$ on treatment for metastatic disease versus $73 \%$ patients in the follow-up period.
With the exception of adjuvant treatment, for about a third of patients across all subgroups, it was the physician who delayed check-ups: $36 \%$ in the total population, $37 \%$ early stages, $32 \%$ advanced stages, $31 \%$ patients in treatment for metastatic disease, $36 \%$ in patients under observation, but only $18 \%$ patients on adjuvant treatment.

Concerning diagnostics - $36 \%$ of the responders had investigations delayed by their healthcare provider, while 55\% postponed tests at their initiative. Imaging was delayed for $19 \%$ of the respondents, 
blood tests for $12 \%$, dermatoscopy for $7 \%$ and histological tests for the most unfortunate $4 \%$.

During the state of emergency, $33 \%$ of respondents managed to receive the treatment on time, very few $(5 \%)$ reporting delays in this respect.

As reasons for the delays, respondents reported: having Covid-like symptoms (some overlapping with the side effects of immunotherapy or targeted therapy); interruption of treatment during Covid-19 infection; difficulty in accessing telephone or online consultation; medical centre closed, the hospital was a hotspot for Covid-19; financial difficulties to travel; fear of contracting Covid-19. Early-stage and stable patients were more likely to give up on their regular consultations, while those with melanoma progression were the most concerned.

Quotes illustrate the challenges: "My oncologist said that we would see each other in 6 months (n.n. for the disease assessment) and this is why I have delayed the dermatological control and the ultrasound" or "I am upset because some radiologists from (..) sent us home with the indication to came back for re-evaluation in three months although my mother scans showed multiple liver, and lung metastasis and adenopathies".

\subsection{Prescriptions at distance during the} state of emergency

In Romania, providing medical services at a distance, such as telemedicine or e- prescriptions is not regulated. However, on 14th of May, an emergency Government Decree allowed prescriptions through electronic means for the period 15th of May30th of September, later extended until the end of the 2020 [15].

In our survey, $18 \%$ participants heard about e-prescriptions from TV news, 34\% via the Romanian Melanoma Association and $19 \%$ from both our organization and TV news.

However, out of the 17 melanoma patients who would have been potentially eligible for e-prescriptions as they were receiving targeted therapy, only half of them succeeded, the other half declaring that the physician rejected their request.

Illustrative examples: "the patient went to the family doctor to pick up her prescription for target therapy because the doctor refused to release the online prescription".

In contrast, this patient "managed to receive target therapy via post mail due to the amiability of the doctor".

\section{Discussion}

These results show that in the absence of a national reporting system, patient communities like the one from Romanian Melanoma Association can generate valuable insights into a specific disease situation at potentially high granularity. This becomes particularly pertinent in emergency situations like the ongoing pandemic. Patient organisations, as well as online patient communities, thereby need to be understood 
as a subset of the overall patient population with distinct self-selecting properties like proactivity and willingness to educate oneself. Based on Facebook's group insights, women and younger patients are expected to be over-represented in the sample. While placing limitations on the degree of representability, we see the particular value of engaged patient communities like ours in their sentinel function that allows to detect issues in patient-care close to real-time. When systematically collected, this specific form of Citizen Science allows to detect both areas in need of improvement as well as best practices, with the opportunity for timely intervention.

Not surprisingly, our results confirm the overall negative impact of Covid-19 on cancer care as reported on a global level by ESMO, ASCO, WHO and World Cancer Surveys also for Romanian melanoma patients. The $\mathrm{RHO}$ with the support of national umbrella organisations has estimated the impact of Covid-19 related measures on chronic diseases, including cancer, and highlighted the dramatic decrease of hospitalisations between AprilSeptember 2020 and their negative effect on patient outcomes [10]. The results of our monitoring pilot now provide a melanomaspecific perspective that is unexpectedly nuanced with regard to patient subpopulations, geography and differences in impact between, e.g. treatment and other interventions and for us an encouraging experience, to develop the concept.
4.1. The pandemic significantly impacted patients' access to melanoma healthcare services

The Covid-19 pandemic has impaired access to healthcare services for $40 \%$ of Romanian Melanoma patients. Comparable data reported by cancer organisations in the Netherlands showed that $30 \%$ cancer patients experienced access issues to their oncological treatment or follow-up [16], making our results consistent with the overall lower performance of the Romanian healthcare system [7-9]. Respondents were either members of our forums or followers, meaning more likely to be proactive, educated patients. Therefore, we consider these results a 'best possible' scenario, with worse outcomes for those patients less able to navigate the Romanian healthcare system. This means that countries with already lower healthcare performance will now be over-proportionally affected by delays in cancer diagnoses. To avoid spiraling out of control of the cancer situation in countries like Romania, we therefore see an urgent need to implement innovative models for early detection to at least dampen the future impact of Covid-19 on outcomes in cancer.

\subsection{Melanoma patients and physicians share safety concerns about Covid-19 \\ Hesitancy in seeking cancer care under} Covid-19 was reported internationally, e.g. in Italy [17] and Netherlands [16]. We saw that over half of patients stated that they 
avoided going to the hospitals for fear of contracting Covid-19 with a notable difference between early versus advanced stages of disease, reflecting the differences in the threat that the disease itself poses. The fact that it was predominantly patients rather than physicians who delayed followup visits and examinations by their own initiative means that even with sufficient protective measures in place, cancer patients will need to be proactively informed and reassured in order to seek care. At the same time, measures for remote early detection should be explored.

\subsection{Feeling safer in private healthcare} facilities

In Romania, there are significant differences between public and private hospitals concerning conditions and organisation, and the number of Romanian patients seeking care to a private healthcare despite at times prohibitive cost facility is increasing [18]. Patients in this study considered private hospitals safer than the public ones (60\% vs $48 \%$ ) regarding triage, safety distance and waiting times. The $\mathrm{RHO}$ reported that the decrease of private hospitals' activity was two times lower than the one of public hospitals in the lockdown period [10] potentially highlighting a higher willingness of the private system to implement protective measures. We are concerned that this will further increase disparities and cancer outcomes between those able to access private- and availablecare versus those relying on publicly funded healthcare facilities.
Also, patients with advanced disease felt safer than patients in early stages to access health services, regardless of the public or private healthcare provider, suggesting that patients' perception of the risk of melanoma affects the perception of safety in healthcare facilities. This requires particular outreach strategies to early stage patients, potentially including alternative means for early detection like application-based screening tools.

In Romania, the initial lack of clarity and consistency in Covid-19 related measures, both at governmental and hospital level [6] added to the cancer patients' safety concerns. Moreover, in March 2020, seventeen healthcare facilities were not logistically prepared to even protect their medical staff, so they experienced serious Covid-19 outbreaks and were forced to close for disinfection [19].

Under Covid-19, we have already witnessed a dramatic decrease of cancer diagnoses across all cancers including melanoma [20]. Tejera-Vaquerizo and Nagore [21] showed that delaying melanoma diagnosis by as little as three months upstages $45 \%$ of patients.

Considering that the pandemic is already lasting longer than initially expected, effective measures for a timely melanoma diagnosis are becoming critical. Effective implementation of an early detection strategy for Melanoma, ideally in a concerted effort with other cancers to avoid competition for attention and maximize reach, appropriate safety measures and communication will be vital to re-establish trust in the system and reach those 
populations whom we have seen most likely to delay seeking care right now.

4.4. From face to face consultation to remote communications and telemedicine

Telecommunication with medical specialists was perceived as easier by metastatic patients than by patients in the early stages. It is reasonable to assume that physicians directed their attention to those with most immediate need. However, considering the risk of delayed diagnosis also for early stages, poor contact with patients in early stages of disease becomes problematic and needs addressing. In our experience, advanced patients are overall better informed about their disease and are more persistent in their relationship with the medical team, but this cannot be assumed for earlier stage patients.

Even before the Covid-19 pandemic, lack of trust and the difficulties in communication between patients and medical staff in Romania were reported [22] and ineffective patient-physician communication is a constant area of concern reported on our patient forums. It is therefore unsurprising that less than half of patients now reported communication with their physicians as unproblematic. Increasing awareness of the existent communication guidelines [23] with adaptation to the current setting would have the potential to improve the quality of the communication between patients and physicians. In particular, the protection of patients' privacy and better management of data safety need to be ensured. The absence of national melanoma guidelines and treatment algorithms thereby constitutes another considerable problem as it hampers efforts to establish consistent communication standards.

The majority of patients contacted their medical team via mobile phone and WhatsApp, with less frequent use of landlines and online forms, potentially caused by the fact that patients reported that cancer facilities did not reply to contact requests via landlines. In contrast, patients noted that some physicians were very responsive to online messaging services such as messenger, demonstrating a growing interest in timely and direct methods of communication in the physician community. In comparison to fully established platforms or telemedicine consultation systems from other European countries, these effects might seem modest but could indicate a promising interest in direct, effective and light-weight patientphysician communication tools for Romania. This would align with our observation of an increasing presence of medical professionals on social media platforms such as Facebook or Twitter, creating communities for general exchange, education and crowd-sourcing for expertise in the sense of second opinions [24]. According to a Cancer World Survey [25] more than four out of ten practitioners initiated patient consultations online and by phone since the start of the Covid-19 pandemic. On the patient side, travel restrictions and lockdowns now also significantly accelerate the uptake of video-conferencing as people try to stay in contact with family and friends. 
Healthcare systems should urgently build on the growing familiarity with online communication tools on all sides as we believe that it is one of the tools that would allow us post-Covid19 not only to optimise care but also to better reach underserved populations.

\subsection{Delays in follow-up likely to} negatively impact patient outcomes

We saw a significant impact of Covid-19 measures on the frequency of follow-up visits for the variety of reasons previously described. In the early disease setting, $8 \%$ of all melanoma patients may develop a secondary melanoma within 2 years of the initial diagnosis and to have an increased risk for other skin tumours [26]. Failure to maintain follow-up in this risk population is therefore highly likely to result in diagnosis at a more advanced stage and by consequence, poorer than normal outcomes.

In the advanced setting, regular high-resolution imaging is critical for disease monitoring and therapy initiation or alteration. Targeted therapy and immunotherapy have proven to be most effective in patients with low tumour burden, so delays in follow-up in imaging are yet again likely to negatively impact outcomes.

The fact that participants in our network have already received a Melanoma diagnosis, explains the rather low percentage of reported delays in biopsies and histopathological tests with only a subset not yet aware of their stage or only at risk of melanoma (Table 1). However, this group of future melanoma patients deserves particular attention as countries with high quality cancer registries like the Netherlands [19] already reported a decrease of early diagnosis in skin cancers. Tejera-Vaquerizo and Nagore [20] estimate that diagnosis delay by one month alone upstages $21 \%$ patients to the next class of Breslow tumour thickness and a delay of 2 or 3 months would upstage $29 \%$ and $45 \%$ of patients respectively. Considering the dramatically decreasing clinical outcomes, the authors therefore highlight the need for urgent measures to ensure timely early detection.

\subsection{Maintained systemic treatments for melanoma patients with advanced disease}

We found the treatment course of patients with metastatic disease to be the least impacted under Covid-19. More than half of our participants were treated with systemic therapies at the time of the survey with very few delays. According to clinical guidelines [26] the majority of our stage III and IV melanoma patients could be treated with either immunotherapy (anti-PD1/antiCTLA4 in combination or monotherapy) or with target therapy (a combination of BRAF/MEK inhibitors), both in adjuvant or metastatic setting. The formulation of targeted therapies (oral) allows treatment at home, while the administration schemes of immunotherapies (infusions) can be modified at reasonable limits without having an impact on efficacy. No patient in our study reported they had radiotherapy (stereotactic 
or whole brain radiotherapy) and very few reported receiving chemotherapy. This contrasts with the relatively high degree with dissatisfaction in this specific patient population with regards to access to healthcare services, most likely due to the particularly high needs of these patients as well as potential side effects.

\subsection{Considerations about surgery}

In our study, only $6 \%$ participants were awaiting melanoma-specific surgeries such as wide excision, Sentinel Lymph Node Biopsies (SLNB) or organ biopsies. Thus, we could not evaluate the particular impact of Covid-19 measures on surgeries. However, in individual cases, the lack of access to organ biopsy- and consequently diagnostic and treatment - led to the progression of disease, despite our efforts to place the patient in a healthcare facility. We suspect that more patients outside our reach were in a critical situation as hospitalizations were dramatically reduced in the period MarchApril 2020 [10].

\subsection{Spontaneous reports in our forums}

Spontaneous patients' reports on our forums reflected alterations to treatment schemes as well as treatment choice such as an increasing trend in the use of target therapy (oral therapy), while the combination of anti-PD/anti-CTLA4 (infusions) seemed even less recommended than before. This is not surprising considering the later recommendations of National Society of
Medical Oncology from Romania (SNOMR) for a prevalent use of oral therapies whenever is feasible [5]. However, avoiding immunotherapies in combinations for the fear of toxicity could harm patients e.g., those with asymptomatic brain metastasis for whom the combination anti-PD/anti-CTLA4 is recommended as most effective [27].

Most melanoma patients on systemic therapy were also acutely aware of SNOMR recommendations regarding the cancellation of their cancer treatment for those whose test positive for Covid-19, this adding to their concerns. While for immunotherapy the decision to discontinue is a reasonable option for patients with complete or partial responses [28], the target therapy interruption could result in the progression of melanoma [29]. Thus, future Covid-19 related recommendations need to be more nuanced with regard to the treatment type and individual risk/benefit ratio, e.g. biological drugs such as PD1s and CTLA4 antibodies and targeted therapies act differently in Covid-19 infected patients than chemo- or radiotherapy [30].

Management of side effects of target therapies and immunotherapies remain an area of great concern. Patients found themselves with little support when experiencing side effects even in situations that could have been easily resolved by telephone advice and e-prescriptions. Some side effects - fever, tiredness and coughingwere more likely not to be reported to physicians. Patients expressed the fear of being suspected of Covid-19 and consequently 
having the oncological treatment interrupted or cancelled.

Getting medical advice and procuring prescriptions for pain medication was another issue reported by melanoma patients and families in our online group. In Romania, opioid medicinal products can be prescribed by physicians within authorized medical units (hospitals, ambulatory care units), but not in all situations the treatment is reimbursed.

Additionally, fears of possible addiction coming from patients combined with lack of adequate training and awareness among healthcare professionals leads to the inappropriate management of cancer pain [31] and unnecessary suffering from those unable to reach their oncologist during Covid-19 pandemic.

Patients on systemic therapies also reported having to travel twice to the cancer centre: one day for Covid-19 test and another day for treatment, exposing them to unnecessary risk as well as additional costs, especially those living at a considerable distance from their treatment centres. As the pandemic continues, measures facilitating cancer patients to be tested in their home town before going for treatment at the specialized centres become pressing.

\section{Concluding recommendations}

While we write this article, a second pandemic wave much stronger than the first one is hitting Romania [32]. On 9th November 2020, Romania had more than 300.000 confirmed Covid-19 cases. The pandemic has already seriously impacted melanoma care in Romania across all stages of disease. To mitigate the potentially even larger impact of the 2nd wave, we urgently recommend to:

- Effective implementation of an early detection strategy for Melanoma, ideally in a concerted effort with other cancers to maximise reach, e.g. certified skin cancer detection apps, gene expression profile tests or blood biomarkers - to early diagnose cancer or its progression during Covid-19 pandemic and beyond.

- Have in place Covid-19 safety measures clearly communicated to everyone. This implies adopting efficient Covid-19 safety models, but also diversifying communication channels and increasing the quality of communication provided by hospitals in order to overcome the hesitancy of patients to visit hospitals or - on contraryavoid congestion of cancer centres.

- Update the National Covid-19 related cancer recommendations. There is a need for refined individual risk stratification strategies according to stage, tumour and treatment type and magnitude of Covid-19 infection to redefine vulnerability and decide interventions in cancer patients.

- Adopt Melanoma high-quality guidelines, recommendations and protocols ideally produced by national experts in national language or implement the international ones (e.g. ESMO Melanoma Guidelines, Melanoma and Essential Requirements for quality Cancer/Melanoma Care) to support the correct management of 
cancer patients both in cancer centres and periphery.

- Implement telemedicine to dramatically improve cancer care and better reach underserved populations. The telemedicine has an enormous potential to support different medical services from screening to treatment planning and followup, as well as side effects and pain management.

- Ensure the access to and continuation of melanoma and cancer care during Covid-19 pandemic by strengthening local capacity to treat patients closer to home. Connect cancer centres with local hospitals, family doctors and Public Health Departments responsible for Covid19 testing.

- Leverage and build on the expertise and reach of patient organizations. Patient communities detect issues early, educate and follow up personally to a degree the healthcare system cannot do it. Online organized communities have a huge potential to systematically collect data and detect opportunities for timely intervention.
- Address fundamental weaknesses in cancer care to increase healthcare system resilience for the future. Poor accessibility to cancer care, inability in providing appropriate and timely treatment, low investments in prevention and early detections are documented issues of Romanian healthcare now severely exacerbated by the Covid-19 pandemic.

Efforts to improve the Romanian healthcare system need to be supported by political will, appropriate financing and infrastructure, systematic education and anti-corruption measures [33]. Changes take time to gain support and acceptance from key stakeholders, but under Covid-19 pandemic circumstances, with a large part of population under the threat, progress can arise faster. Therefore, Romanian authorities could use the pandemic as an opportunity to create new patterns that allow for more rapid and structural reforms in our healthcare system.

\footnotetext{
Abbreviations:

ASCO - American Society of Clinical Oncology

$\mathrm{EHCl}$ - Euro Health Consumer Index

ESMO - European Society of Medical Oncology

COPAC - Coalition of Patient Organizations with Chronic Diseases

RHO - Romanian Health Observatory

SNOMR - National Society of Medical Oncology Romania

WHO - World Health Organization
} 


\section{Statements:}

\section{Authors' contributions:}

VA initiated the research project, co-designed the survey, interpreted the data and wrote the manuscript with input from all authors.

ASD contributed to the survey's design, processed the data and wrote the Methods and Results sections.

$\mathrm{BR}$ revised the overall manuscript concept, offered direction to the Discussion and Recommendations section.

Consent for publication: As the corresponding author, I confirm that the manuscript has been read and approved for submission by all co-authors.

Funding sources: This research was made possible through unremunerated work of the authors.

Conflict of interest: Neither MR, MPNE, nor any of the authors received remuneration in relation to the presented work. In the last 5 years, MR received conference grants and consultancy fees from Amgen, BMS, MSD, Novartis, and Roche without being related to the submitted work. MPNE received grants from Amgen, BMS, Delcath, Immunocore, Merck, MSD, Novartis, Pierre Fabre, Roche for their network activities. A.S.D reports no conflict of interest. BR reports consultancy fees from Amgen, BMS, MSD, Novartis, Pfizer. V.A. received consultancy fees from Amgen and Novartis.

Statement of Ethics: The accompanying manuscript does not contain any studies carried out by the authors on humans or animals.

Acknowledgments: We thank the patients and their families who answered our survey, allowed us to continuously monitor pertinent issues and who as a community helped us address recommendations in melanoma care.

\section{References:}

1. WHO. COVID-19 significantly impacts health services for noncommunicable diseases. https://www.who.int/news/item/01-06-2020-covid-19-significantly-impacts-health-services- for-noncommunicablediseases (n.d.).

\section{ASCO SPECIAL REPORT:}

https://www.asco.org/sites/new-www.asco.org/files/content-files/2020-ASCO-Guide-Cancer-COVID19.pdf (n.d.).

3. Managing cancer patients during the COVID-19 pandemic. https://www.esmo.org/guidelines/cancer-patientmanagement-during-the-covid-19-pandemi c/consensus-recommendations-managing-cancer-patients-during-thecovid-19-pandemic (n.d.). 
4. Ordonanța-militară-nr.-1-2020-măsuri-de-prima-urgență-Decret.pdf. https://bit.ly/3fODIKF (n.d.).

5. Măsuri recomandate în vederea reducerii impactului pandemiei COVID-19 asupra pacienților oncologici și asupra serviciilor de oncologie - SNOMR - site oficial Societatea Națională de Oncologie Medicală din România.

https://snomr.ro/masuri-recomandate-reducerii-impactului-pandemiei-covid-19-asupra-paci entilor-oncologiciasupra-serviciilor-de-oncologie/ (n.d.).

6. Victimele colaterale ale războiului cu coronavirusul: "M-am simțit aruncată direct la cimitir" - Recorder. https://recorder.ro/victimele-colaterale-ale-razboiului-cu-coronavirusul-m-am-simtit-aruncata-direct-la-cimitir/ (n.d.).

7. Euro Health Consumer Index 2018. https://healthpowerhouse.com/media/EHCl-2018/EHCl-2018-report.pdf (n.d.).

8. Euro Health Consumer Index 2017. https://healthpowerhouse.com/media/EHCl-2017/EHCl-2017-report.pdf (n.d.).

9. Euro Health Consumer Index 2016. https://healthpowerhouse.com/media/EHCl-2016/EHCl-2016-report.pdf (n.d.).

10. Impactul Pandemiei COVID 19 asupra bolnavilor cronici_septembrie 2020-1.docx. https://healthobservatory.ro/wp-content/uploads/2020/10/Raport_ORS-impact_pandemie_c ronici_2020.pdf (n.d.).

11. Data explorer | ECIS. https://ecis.jrc.ec.europa.eu/explorer.php (n.d.).

12. Suteu, O. et al. Incidence trends and survival of skin melanoma and squamous cell carcinoma in Cluj County, Romania. Eur J Cancer Prev 26, S176-S182 (2017).

13. Forsea, A. M., Marmol, V. del, Vries, E. de, Bailey, E. E. \& Geller, A. C. Melanoma incidence and mortality in Europe: new estimates, persistent disparities. British Journal of Dermatology 167, 1124-1130 (2012).

14. Larkin, J. et al. Five-Year Survival with Combined Nivolumab and Ipilimumab in Advanced Melanoma. New Engl J Med 381, 1535-1546 (2019).

15. COMUNICAT - Din 1 octombrie cardul de sănătate redevine obligatoriu, cu excepția consultațiilor la distanță. http://www.cnas.ro/post/type/local/comunicat-din-1-octombrie-cardul-de-sanatate-redevine- obligatoriu-cuexceptia-consultatiilor-la-dist.html (n.d.).

16. Impact of the coronavirus disease 2019 pandemic on cancer treatment: the patients' perspective - European Journal of Cancer.

https://www.ejcancer.com/article/S0959-8049(20)30352-X/fulltext (n.d.).

17. Filippo, O. D. et al. Reduced Rate of Hospital Admissions for ACS during Covid-19 Outbreak in Northern Italy. New Engl J Med 383, 88-89 (2020).

18. Public vs. private: healthcare services and subscriptions. https://analytica.questiagroup.com/public-privatehealthcare/ (n.d.).

19. 17 spitale din România atinse de coronavirus, peste 150 de cadre medicale infectate, alte zeci așteaptă rezultatul testelor.

https://romania.europalibera.org/a/spitale-din-rom\%C3\%A2nia-atinse-de-coronavirus-peste

-150-de-cadre-medicale-infectate-alte-zeci-a\%C8\%99teapt\%C4\%83-rezultatul-testelor/305 12791.html (n.d.).

20. Dinmohamed, A. G. et al. Fewer cancer diagnoses during the COVID-19 epidemic in the Netherlands. Lancet Oncol 21, 750-751 (2020). 
21. Estimated effect of COVID\&\#x02010;19 lockdown on melanoma thickness and prognosis: a rate of growth model. https://europepmc.org/backend/ptpmcrender.fcgi?accid=PMC7267312\&blobtype=pdf (n.d.).

22. Interpersonal communication within Romanian medical field - ARS. http://www.journalstudiesanthro pology.ro/en/interpersonal-communication-within-romanian-medical-field/a87/ (n.d.).

23. Gilligan, T. et al. Patient-Clinician Communication: American Society of Clinical Oncology Consensus Guideline. J Clin Oncol 35, JCO.2017.75.231 (2017).

24. Major Achievements | ESMO.

https://www.esmo.org/about-esmo/organisational-structure/young-oncologists-committee/Major-Achievements (n.d.).

25. Delivering cancer care during the pandemic: lessons from the 'first wave' - Cancerworld.

https://cancerworld.net/spotlight-on/delivering-cancer-care-during-the-pandemic-lessons-fr om-the-first-wave/ (n.d.).

26. Cutaneous melanoma: ESMO Clinical Practice Guidelines for diagnosis, treatment and follow-up. https://www.annalsofoncology.org/article/S0923-7534(20)32563-1/pdf (n.d.).

27. Tawbi, H. A. et al. Combined Nivolumab and Ipilimumab in Melanoma Metastatic to the Brain. New Engl J Med 379, 722-730 (2018).

28. Durable Complete Responses After Discontinuation of Immunotherapy in Metastatic Melanoma - The ASCO Post. https://ascopost.com/News/58433 (n.d.).

29. Carlino, M. S. et al. Cessation of targeted therapy after a complete response in BRAF-mutant advanced melanoma: a case series. Brit J Cancer 115, 1280-1284 (2016).

30. Vivarelli, S. et al. Cancer Management during COVID-19 Pandemic: Is Immune Checkpoint Inhibitors-Based Immunotherapy Harmful or Beneficial? Cancers 12, 2237 (2020).

31. Bosetti, C. et al. Trends in the consumption of opioids for the treatment of severe pain in Europe, 19902016. Eur J Pain 23, 697-707 (2019).

32. Buletin informativ 09.11.2020 - Ministerul Sănătății. http://www.ms.ro/2020/11/09/buletin-informativ-09-112020/ (n.d.).

33. Patients are denied care because of corruption in Romania. https://www.thelancet.com/pdfs/journals/ lancet/PIIS0140-6736(17)32811-8.pdf (n.d.). 